\title{
National Multicenter and Multiyear Review of Complications Following Fluoroscopic Gastrostomy in Patients Covered by Medicare and Medicaid
}

\author{
Ulku C. Turba' Bulent Arslan¹
}

Syed I. Khalid ${ }^{1}$ Rita Wu² Jordan C. Tasse ${ }^{1}$ David M. Tabriz ${ }^{1} \quad$ Sreekumar Madassery ${ }^{1}$

\begin{abstract}
Address for correspondence Syed I. Khalid, MD, Division of Interventional Radiology, Rush University Medical Center, Professional Building, 1725 W. Harrison St., Suite 450, Chicago, IL 60612, United States (e-mail: syed.khalid@me.com).
\end{abstract}

\begin{abstract}
Keywords

- gastrostomy

- G-tube

- percutaneous endoscopic gastrostomy

- endoscopic

- fluoroscopic

Objective This study aims to assess the postoperative complication rates associated with fluoroscopically placed gastrostomy tubes.

Background Fluoroscopically placed gastrostomy tubes are a relatively common procedure performed by interventional radiologists. Few studies have been performed in the United States to access the complication profile of fluoroscopically placed gastrostomy tubes.

Methods Total 51 million Medicare Standard Analytic Patient Records derived from Medicare parts A and B records from 2007 to 2012 were retrospectively analyzed. Only the patients undergoing fluoroscopic gastrostomy were included in this study. Patient demographics were stratified by age, sex, comorbidities, and peri- and postoperative complications as defined by International Classification of Diseases (ICD) 9 codes.

Results Total 30,327 patients undergoing fluoroscopic gastrostomy were analyzed. Perioperative complications following these procedures were low, with 61 (0.02\%) patients experiencing pneumoperitoneum, 130 (0.43\%) experiencing ileus, 16 $(0.05 \%)$ experiencing esophageal/gastric perforation, and $30(0.09 \%)$ patients experiencing intra-abdominal injury. Most common postoperative complications included abdominal wall pain $(n=2,808,9.25 \%)$, bleeding $(n=1,353,4.46 \%)$, and mechanical complications ( $n=1,435,4.73 \%)$.

Conclusion Fluoroscopic guidance is a safe method for gastrostomy placement, with exceedingly low rates of peri- and postoperative complications.
\end{abstract}

\section{Introduction}

Gastrostomy tubes have been used for $>100$ years in patients requiring enteral nutrition for an extended period of time. ${ }^{1}$ Traditionally, gastrostomy tubes were placed surgically under general anesthesia in the operating room. ${ }^{2}$ Since then, however, new techniques that are simpler to perform and require only local anesthesia such as percutaneous endoscopic insertion and fluoroscopically guided insertion have emerged and mostly displaced traditional surgery from clinical practice. ${ }^{3-7}$ Early studies of both minimally invasive techniques have shown high success rates and low peri- and postoperative complication rates. ${ }^{8-11}$ However, much of the current literature on fluoroscopic gastrostomy, in particular, has been limited to being outside of the United States or performed in a single institution or region. ${ }^{7,8,12-19}$ This study aims to evaluate the complication rates associated fluoroscopically placed gastrostomy tubes nationally in patients covered by Medicare parts A and B in the United States.
License terms

()(1) $\Theta \circledast$ 


\section{Methods}

Medicare Standard Analytic Files containing 100\% of inpatient and outpatient facility records billed to Medicare from 2007 to 2012 were retrospectively analyzed. Total 30,327 patients were identified as having undergone fluoroscopic gastrostomy placement defined by Current Procedural Terminology (CPT) codes CPT-49440. Patients were stratified by age, sex, and comorbidities. Presence of comorbidities: diabetes mellitus (DM), hypertension (HTN), hyperlipidemia (HLD), atrial fibrillation (a-fib), obesity, history of smoking/smoker, and/ or history of cancer; perioperative complications: pneumoperitoneum, ileus, esophageal and gastric perforation, and/or damage to other intra-abdominal organs; and postoperative complications: mechanical complication of gastrostomy, other gastrostomy complications, surgical site infection, necrotizing fasciitis, bleeding, ulceration, gastric outlet obstruction, colocutaneous fistula, and/or abdominal wall pain were defined by International Classification of Diseases (ICD) 9 codes (detailed in Supplementary Tables S1-S3, online only).

\section{Results}

Total 30,327 patients were identified as undergoing fluoroscopic gastrostomy. Regional breakdown of patients represented include 6,042 from the mid-west; 5,014 from the northeast; 12,146 from the south; 7,124 from the west; and 1 unknown with $>2,031$ hospital centers represented. Age breakdown is noted (-Table 1) with most patients age ${ }^{3}$ 65 years $(70.48 \%$ ). Males made up $53.66 \%$ of the population ( $n=16,272$ ). Prevalence of comorbidities noted in patient group showed $38.81 \%$ with DM $(n=11,771), 77.16 \%$ with HTN $(n=23,401), 58.68 \%$ with $\operatorname{HLD}(n=17,795), 23.44 \%$ with a-fib ( $n=7,111), 2.27 \%$ with obesity $(n=689), 37.26 \%$ with history of smoking ( $n=11,299)$, and $28.32 \%$ with history of cancer $(n=8,589)$.

Incidences of perioperative complications noted showed $0.20 \%$ with pneumoperitoneum ( $n=61), 0.43 \%$ with ileus $(n=130), 0.05 \%$ with esophageal/gastric perforation $(n=16)$, and $0.09 \%$ with intra-abdominal injury $(n=30)$. Incidences of 30-day postoperative complications showed $4.73 \%$ with mechanical complications $(n=1,435), 2.73 \%$ with other gastrostomy complications ( $n=828$ ), $1.46 \%$ with surgical site infection ( $n=443$ ), $0 \%$ with necrotizing fasciitis $(n=1), 4.46 \%$ with bleeding ( $n=1,353), 0.06 \%$ with ulceration $(n=17)$, $0.30 \%$ with outlet obstruction ( $n=92), 0.22 \%$ with colocutaneous fistula ( $n=67)$, and $9.25 \%$ with abdominal wall pain $(n=2,808)($-Table 1).

\section{Discussion}

Our analysis of 30,327 patients undergoing fluoroscopic gastrostomy showed low rates of perioperative complications. An early retrospective study by Hicks et al on 158 patients undergoing fluoroscopic gastrostomy reported rate of ileus large gastric residual at $4 \%(n=6) .{ }^{6} \mathrm{~A}$ later retrospective study by Neeff et al of 18 fluoroscopic gastrostomy patients reported a similar rate of ileus at $5.6 \%$
Table 1 Descriptive characteristics of patients undergoing fluoroscopic gastrostomy placement

\begin{tabular}{|c|c|}
\hline & $\mathrm{N},(\%)$ \\
\hline Total procedures & 30,327 \\
\hline \multicolumn{2}{|l|}{ Age (y) } \\
\hline Unknown & $274(0.90)$ \\
\hline$\leq 64$ & $6,224(20.52)$ \\
\hline $65-69$ & $5,142(16.96)$ \\
\hline $70-74$ & $4,782(15.77)$ \\
\hline $75-79$ & $4,345(14.33)$ \\
\hline $80-84$ & $4,278(14.11)$ \\
\hline$\geq 85$ & $5,282(17.42)$ \\
\hline \multicolumn{2}{|l|}{ Sex } \\
\hline Male & $16,272(53.66)$ \\
\hline Female & $13,780(45.44)$ \\
\hline Unknown & $275(0.91)$ \\
\hline \multicolumn{2}{|l|}{ Comorbidities } \\
\hline Diabetes & $11,771(38.81)$ \\
\hline Hypertension & $23,401(77.16)$ \\
\hline Hyperlipidemia & $17,795(58.68)$ \\
\hline Atrial fibrillation & $7,111(23.44)$ \\
\hline Obesity & $689(2.27)$ \\
\hline History of smoking & $11,299(37.26)$ \\
\hline History of cancer & $8,589(28.32)$ \\
\hline
\end{tabular}

$(n=1) . .^{13}$ Our study noted much lower rates of ileus with $130(0.43 \%)$ patients only. A randomized controlled study by Cosentini et al of 44 patients undergoing fluoroscopic gastrostomy noted rate of pneumoperitoneum at $18 \%$ $(n=8))^{7}$ Rates of perioperative esophageal/gastric perforation or other intra-abdominal injury have not been specifically reported in previous literature. Our study noted low rates of both esophageal/gastric perforation $(n=16,0.05 \%)$ and intra-abdominal injury ( $n=30,0.09 \%)$.

Our analysis of postoperative complications following fluoroscopic gastrostomy was similarly low and mostly in concordance with reported rates in the literature. An early randomized control study of 66 patients by Hoffer et al reported five patients with mechanical failure of either tube dislodgement, fracture, leakage, or block (7.6\%), five with wound infection (7.6\%), none with bleeding $(0 \%)$, and one with ulceration (1.5\%). ${ }^{8}$ A later retrospective study of 193 patients by Silas et al similarly reported three patients with mechanical failure of dislodgement or leakage (1.7\%), four with wound infection (2.3\%), and three with pain (4\%). ${ }^{20}$ Rates of postoperative complications of "other gastrostomy complications" such as tumor seeding or herniation, necrotizing fasciitis, gastric outlet obstruction, or colocutaneous 
fistula have not been reported in the literature history. Our findings of postoperative complications following fluoroscopic gastrostomies were comparable with 1,435 patients experiencing mechanical complications (4.73\%), 828 experiencing "other gastrostomy complications" (2.73), 443 experiencing infection (1.46\%), 1 experiencing necrotizing fasciitis (0\%), 17 experiencing ulceration (0.06\%), 92 experiencing outlet obstruction (0.030\%), 67 experiencing colocutaneous fistula (0.2\%), and 2,808 patients experiencing abdominal pain (9.25\%).

Overall, the peri- and postoperative complication rates of fluoroscopic gastrostomies in this study are similar to those reported in the literature. Summary of the previous studies note rates of ileus at $4 \%$; rates of mechanical failure including removal, leakage, and dysfunction ranging at 1 to $6.2 \% 6,8,10,20,21$; rates of infection ranging at 3 to $7.6 \%$,20,21; rates of bleeding ranging at 0 to $3 \%$, 8 ; rates of ulceration at $1.5 \%$; and rates of pain at $1.6 \%{ }^{20}$ Of note, the aforementioned studies were limited to those performed in a hospital or surgical center located in the United States only. Past studies performed outside of the United States noted interestingly higher rates of complications for mechanical failure ranging at 2.9 to $38 \%, 7,13,16,22$ rates of infection at 3 to $22 \%,{ }^{7,13-15}$ and rates of pain at $35 \%,{ }^{14}$ though differing standards of practice and patient criteria may account for these differences. Our study showed relatively low rates of complications, with rates of abdominal pain (9.25\%), bleeding (4.46\%), and mechanical failure (4.73\%) being the most common. Our reported rates of infection were considerably lower than those reported in the literature $(1.46 \%$ in our study vs. range of $3-7.6 \%$ in the literature).

\section{Limitations}

Though the use of administrative data allows for access to large numbers of medical data files across national hospitals with long-term tracking within the coding system, analysis of such data does not allow for controls for individual procedural methods, surgeon expertise, standardization of quality of care, or insight into criteria for selection of patients. Administrative data are typically meant for administrative and financial purposes rather than research, which may subject such data to errors in accuracy and comprehensiveness due to reliance on interpretation of physician records by a medical reviewer.

\section{Conclusion}

Fluoroscopic guidance for gastrostomy placement is a safe procedure with low rates of peri- and postoperative complications.

\section{Institutional Approval}

This study was approved by the institutional review board (IRB)-study number PDUVA001820.

\section{Conflicts of Interest}

No authors have conflicts to disclose.
Table 2 Rates of peri- and postoperative complications following fluoroscopic gastrostomy

\begin{tabular}{|l|l|}
\hline & N, (\%) \\
\hline Perioperative complications & \multicolumn{1}{|l|}{} \\
\hline Pneumoperitoneum & $61(0.20)$ \\
\hline Ileus & $130(0.43)$ \\
\hline Esophageal/gastric perforation & $16(0.05)$ \\
\hline Intra-abdominal injury & $30(0.09)$ \\
\hline & \\
\hline Postoperative complications & $1435(4.73)$ \\
\hline Mechanical complication & $828(2.73)$ \\
\hline Other gastrostomy complication & $443(1.46)$ \\
\hline Surgical site infection & $1(0)$ \\
\hline Necrotizing fasciitis & $1353(4.46)$ \\
\hline Bleeding & $17(0.06)$ \\
\hline Ulceration & $92(0.30)$ \\
\hline Gastric outlet obstruction & $67(0.22)$ \\
\hline Colocutaneous fistula & $2808(9.25)$ \\
\hline Abdominal wall pain & \\
\hline
\end{tabular}

\section{References}

1 O'Brien B, Davis S, Erwin-Toth P. G-tube site care: a practical guide. RN 1999;62(2):52-56

2 Eisenberg PG. Gastrostomy and jejunostomy tubes. RN 1994;57(11):54-59; quiz 60. Available at: http://www.ncbi. nlm.nih.gov/pubmed/7984882. Accessed December 22, 2018

3 Preshaw RM. A percutaneous method for inserting a feeding gastrostomy tube. Surg Gynecol Obstet 1981;152(5):658-660

4 Gibson SE, Wenig BL, Watkins JL. Complications of percutaneous endoscopic gastrostomy in head and neck cancer patients. Ann Otol Rhinol Laryngol 1992;101(1):46-50

5 Larson DE, Burton DD, Schroeder KW, DiMagno EP. Percutaneous endoscopic gastrostomy. Indications, success, complications, and mortality in 314 consecutive patients. Gastroenterology 1987;93(1):48-52

6 Hicks ME, Surratt RS, Picus D, Marx MV, Lang EV. Fluoroscopically guided percutaneous gastrostomy and gastroenterostomy: analysis of 158 consecutive cases. AJR Am J Roentgenol 1990;154(4):725-728

7 Cosentini EP, Sautner T, Gnant M, Winkelbauer F, Teleky B, Jakesz R. Outcomes of surgical, percutaneous endoscopic, and percutaneous radiologic gastrostomies. Arch Surg 1998;133(10):1076-1083

8 Hoffer EK, Cosgrove JM, Levin DQ, Herskowitz MM, Sclafani SJA. Radiologic gastrojejunostomy and percutaneous endoscopic gastrostomy: a prospective, randomized comparison. J Vasc Interv Radiol 1999;10(4):413-420

9 Richter-Schrag HJ, Richter S, Ruthmann O, Olschewski M, Hopt UT, Fischer A. Risk factors and complications following percutaneous endoscopic gastrostomy: a case series of 1041 patients. Can J Gastroenterol 2011;25(4):201-206

10 Lewis S, Jackson S, Latchford A. Randomized study of radiologic vs endoscopic placement of gastrojejunostomies in patients at risk of aspiration pneumonia. Nutr Clin Pract 2014;29(4):498-503 
11 McDermott CJ; ProGas Study Group. Gastrostomy in patients with amyotrophic lateral sclerosis (ProGas): a prospective cohort study. Lancet Neurol 2015;14(7):702-709

12 Barkmeier JM, Trerotola SO, Wiebke EA, et al. Percutaneous radiologic, surgical endoscopic, and percutaneous endoscopic gastrostomy/gastrojejunostomy: comparative study and cost analysis. Cardiovasc Intervent Radiol 1998;21(4):324-328

13 Neeff M, Crowder VL, Mclvor NP, Chaplin JM, Morton RP. Comparison of the use of endoscopic and radiologic gastrostomy in a single head and neck cancer unit. ANZ J Surg 2003;73(8):590-593

14 Desport JC, Mabrouk T, Bouillet P, Perna A, Preux PMCP, Couratier P. Complications and survival following radiologically and endoscopically-guided gastrostomy in patients with amyotrophic lateral sclerosis. Amyotroph Lateral Scler Other Motor Neuron Disord 2005;6(2):88-93

15 Galaski A, Peng WW, Ellis M, Darling P, Common A, Tucker E. Gastrostomy tube placement by radiological versus endoscopic methods in an acute care setting: a retrospective review of frequency, indications, complications and outcomes. Can J Gastroenterol 2009;23(2):109-114

16 La Nauze RJ, Collins K, Lyon S, et al. Outcomes of percutaneous endoscopic gastrostomy versus radiologically inserted gastrostomy tube insertion at a tertiary hospital. ESPEN J 2012;7(4):144-148
17 Laskaratos FM, Walker M, Walker M, et al. Predictive factors for early mortality after percutaneous endoscopic and radiologically-inserted gastrostomy. Dig Dis Sci 2013;58(12):3558-3565

18 Lim JH, Choi SH, Lee C, et al. Thirty-day mortality after percutaneous gastrostomy by endoscopic versus radiologic placement: a systematic review and meta-analysis. Intest Res 2016;14(4):333-342

19 Strijbos D, Keszthelyi D, Bogie RMM, et al. A systematic review and meta-analysis on outcomes and complications of percutaneous endoscopic versus radiologic gastrostomy for enteral feeding. J Clin Gastroenterol 2018;52(9):753-764

20 Silas AM, Pearce LF, Lestina LS, et al. Percutaneous radiologic gastrostomy versus percutaneous endoscopic gastrostomy: a comparison of indications, complications and outcomes in 370 patients. Eur J Radiol 2005;56(1):84-90

21 Wollman B, D'Agostino HB. Percutaneous radiologic and endoscopic gastrostomy: a 3-year institutional analysis of procedure performance. AJR Am J Roentgenol 1997;169(6):1551-1553

22 Eze N, Jefford JM, Wolf D, Williamson P, Neild P. PEG and RIG tube feeding in Head and Neck patients: a retrospective review of complications and outcome. J Eval Clin Pract 2007;13(5):817-819 